\title{
A Differential Psychro Test of Plant-Soil-Weather Relationships and Water Use
}

\author{
Modesto Capiel ${ }^{2}$ \\ INTRODUCTION
}

There is great need for high efficiency in all aspects of agriculture. Crop production is an area possibly most susceptible to improvement. Plantwater relationships thus are an important phase of investigation because crop yields exhibit marked and widespread responses to irrigation, due mainly to the employment of better plant-water techniques.

Although diurnal changes in leaf resistance to water vapor diffusion are known to exist, Gardner and Nieman (2) showed that the impedance in the soil is greater than the impedance in the plant, even in relatively wet soils. The impedance in the soil is primarily related to the capillary conductivity of the soil and to the effective root distribution per unit volume.

Some diurnal studies conducted by Werner (6) suggest that the relative water content of leaves was influenced chiefly by the vapor pressure deficit of the atmosphere. Seasonal studies conducted by Namken (4) indicate that approximately 88 percent of the variations in relative water content of cotton leaves was due to changes in soil water content, air temperature and pan evaporation. However, pan evaporation and air temperature should not be treated as independent parameters, as both are integrating expressions that encompass the same or similar variables.

Miller et al. (3) recently studied the influence of atmospheric and soil environmental parameters on the diurnal fluctuations of the leaf water status of barley. The leaf water potential was found to exhibit the most significant inverse correlation with the soil surface temperature, among all other environmental parameters. Yet, leaf water content correlated slightly better than the leaf water potential with the other environmental parameters. At the same time, correlations were higher with the soil near the wilting point than near field capacity.

However, both the leaf water potential measurements with a thermocouple psychrometer and relative leaf water content measurements made gravimetrically require interference with the plant material.

Capiel (1) also evaluated a differential psychrometric method under lab-

1 Manuscript submitted to Editorial Board April 20, 1972.

2 Agricultural Climatologist, Agricultural Engineering Department, Agricultural Experiment Station, University of Puerto Rico, Río Piedras, P. R. The author is grateful to Dr. Saulo J. Rodriguez, Horticulturist, for his assistance and advice rendered in the selection of the experimental material. 
oratory conditions for scheduling irrigation needs. The method essentially consists in recording a thermocouple potential as a result of the difference in evaporative cooling between a non-ventilated wet-bulb thermojunction at the height of a crop canopy, and an increasingly less intensive evaporative cooling at the junction (dry-bulb) on the soil surface as evaporation proceeds after a given irrigation. A significant interaction between the vapor pressure deficit, the moisture content of the matrix material surrounding the dry bulb, and the evaporation rate from its surface, accounted for 81 percent of the variations in the recorded thermo-potential.

This paper presents an evaluation of the differential psychrometric method under greenhouse conditions, so that the soil, plant and the atmospheric environmental effects related to irrigation needs can be appraised simultaneously.

\section{MATERIALS AND METHODS}

In a small greenhouse, $25 \mathrm{~m} .{ }^{2}$ in floor area, bean plants (Bountiful and white field varieties), and coffee plants (Bourbon) were grown in clay pots for the duration of the experiment, 28 days. The bean plants were about 15 days old when the experiment began; the coffee plants had been growing for about 5 months and had developed the first two lateral shoots. The greenhouse was fan-ventilated and dehumidified from 0700 to 1800 hours. Air temperature inside varied from $23^{\circ} \mathrm{C}$. at night to $35^{\circ} \mathrm{C}$. somewhat after noon on warmer days. Relative humidity also fluctuated from $\mathbf{5 7}$ percent during the day to about 85 percent during the night. Wind movement changed generally from about $2.5 \mathrm{~km}$. per hour at the height of the crop canopies in the daytime to almost none at night.

Six pots each of beans and coffee plants were selected for the study; these were surrounded by additional pots containing bean and coffee plants. All pots contained a plastic clay loam or silty clay loam mixed with filter press cake in equal parts. Surface soil in each pot was paraffin-sealed to prevent surface evaporation. Adequate aeration was possible under the pots and between pot walls and the soil. Two sealed, plant-free pots (blanks) were kept to correct for any other evaporation from pot walls.

The plants were watered during nighttime by leaving the pots in aluminum dishes filled with water, so that the soil could be soaked by capillary conductivity. Irrigation was based on two regimes; a frequent one after an approximate accumulation of 1,200 langleys of solar radiation, and a less frequent one based on an accumulation of around 2,500 langleys of solar radiation measured under the greenhouse roof with an Eppley pyrheliometer. Three pots of coffee and three of beans were allocated to each of the two irrigation regimes.

In addition to solar radiation, continuous recordings were made of the 
air temperature, relative humidity and the net solar radiation measured with a Fritschen miniature net radiometer. The vapor pressure deficit was calculated from measurements of temperature and relative humidity.

The experimental pots were weighed once or twice a day to sample time intervals of consistently high, medium and low evaporative demands, and at the same time obtain representative mean weights of each pot based on reasonably close initial and final weights. The oven-dry weight of the soil in each pot was also calculated to determine the moisture content of the soil at any given time. In addition, the total leaf area was calculated at 4-day intervals so that the actual leaf area representative of a shorter interval could be approximated linearly.

The mean evaporation from the two blank soil surface paraffin-sealed pots was subtracted from the total moisture loss from the pots on a given time interval, to more closely approximate the apparent transpiration rate, obtained by dividing the $\mathrm{cm}^{2}$ of water lost by the leaf area in $\mathrm{cm}^{2}$. Therefore, from each of the 12 bean and coffee pots, measurements were obtained for every sampling interval for the transpiration rate $(T s p)$ in $\mathrm{mm}$. per day, the actual evapotranspiration rate $\left(E t_{a}\right)$ in $\mathrm{cm}^{3}$ per day and the soil moisture content by weight $(\theta)$ in percent. Also obtained for the same time intervals were the mean values of net solar radiation $\left(R_{n}\right)$ in $\mathrm{mm}$. per day the air temperature $\left(T_{a}\right)$ in degrees centigrade, the vapor pressure deficit $\left(e_{d}\right)$ in $m b$, and the wind speed $(u)$ in $\mathrm{km}$. per day. With these tabulated values, the potential evapotranspiration $\left(E t_{p}\right)$, in $\mathrm{mm}$. per day was estimated from Penman's equation (5).

The thermocouple potential $(\Delta t)$ was obtained by use of the technique described by Capiel (1). In this case one cylindrical plug containing the "hot" (dry bulb) thermojunction, flush with the upper flat surface of the plug, was located on each pot so that the thermojunction would also be flush with the soil surface, although the upper flat surface of the plug was not covered with paraffin. The wet bulb or reference junction was located at the mean height of the plants-in-pot canopy. The continuous recording of $\Delta t$, along the time intervals during which the soil, plant, and atmospheric parameters were averaged, was made simultaneously on two pots-coffee and beans, or either plant twice. This was made possible with a 1-minute cyclic timer, allowing 30 seconds on and off on each pot. The paired pots were kept recording for about 4 days, generally connected to the recording system the day after a night-time sub-irrigation. Thus, each of the 12 pots was sampled for $\Delta t$ and all other measurements at least once during the 28-day experimental period.

The mean recorded differential temperature $(\Delta t)$ was evaluated as a func-

8 One mm. per day is equivalent to 58.14 langleys per day. 
tion of soil, plant and weather factors by simple and multiple regression analysis. This provides a means of investigating the involvement and possible interaction of the three groups of parameters in establishing an integrated basis of irrigation needs.

\section{RESULTS AND DISCUSSION}

The mean values of the soil, plant and atmospheric parameters $(\theta, T s p$, $\left.E t_{a}, E t_{p}, R_{n}, e_{d}, T_{a}, u\right)$ of the coffee and bean plant pots, corresponding to 43

TABLE 1.-Mean values of the recorded potential $(\Delta t)$ integrated with time, as well as the corresponding mean values of the main soil, plant and weather components used to evaluate $\Delta$ t on bean plants growing in pots until the bloom stage

\begin{tabular}{|c|c|c|c|c|c|c|c|}
\hline$\Delta t$ & $\theta$ & $T s p$ & $E l_{p}$ & $R_{n}$ & $E l_{a}$ & $e_{d}$ & $T_{a}$ \\
\hline$\mu, h_{0} \cdot-1$ & Percent & $M m \cdot d_{a y-1}$ & $M m \cdot d a y^{-1}$ & $M m, d a y^{-1}$ & $C m .^{2} d a y^{-1}$ & $M B$ & ${ }^{\circ} \mathrm{C}$ \\
\hline 137 & 42.3 & 7.53 & 6.64 & 6.91 & 627 & 18.38 & 32.3 \\
\hline 80 & 38.4 & 0.85 & 1.06 & 0.72 & 96 & 11.47 & 28.2 \\
\hline 97 & 35.9 & 3.96 & 3.31 & 3.25 & 360 & 11.82 & 29.3 \\
\hline 56 & 33.8 & 0.36 & 0.75 & 0.50 & 48 & 7.09 & 25.3 \\
\hline 98 & 31.0 & 5.60 & 5.07 & 5.53 & 560 & 11.35 & 29.2 \\
\hline 86 & 22.9 & 1.59 & 1.87 & 1.76 & 200 & 10.06 & 27.5 \\
\hline 159 & 14.7 & 1.08 & 2.98 & 2.92 & 158 & 14.09 & 29.7 \\
\hline 108 & 43.2 & 5.03 & 6.04 & 6.28 & 891 & 17.12 & 32.1 \\
\hline 107 & 37.5 & 0.63 & 1.13 & 0.82 & 135 & 10.60 & 27.2 \\
\hline 80 & 32.2 & 1.24 & 1.70 & 1.52 & 240 & 9.80 & 27.0 \\
\hline 73 & 26.9 & 2.21 & 3.01 & 3.00 & 431 & 10.06 & 28.2 \\
\hline 41 & 45.7 & - & 0.96 & 0.72 & - & 8.26 & 26.2 \\
\hline 34 & 43.9 & 4.35 & 4.57 & 4.89 & 661 & 11.34 & 29.5 \\
\hline 72 & 41.4 & 2.60 & 2.80 & 2.38 & 365 & 14.60 & 31.0 \\
\hline 5 & 39.8 & 0.52 & 1.01 & 0.80 & 82 & 7.71 & 25.3 \\
\hline 38 & 32.5 & 2.46 & 2.50 & 2.38 & 327 & 11.82 & 29.3 \\
\hline 50 & 14.1 & 0.36 & 1.58 & 1.34 & 82 & 10.58 & 27.4 \\
\hline 160 & 11.6 & 1.28 & 5.63 & 6.22 & 250 & 11.11 & 30.8 \\
\hline 141 & 10.4 & 0.26 & 2.40 & 2.38 & 60 & 11.28 & 29.1 \\
\hline 210 & 9.4 & 0.73 & 6.02 & 6.83 & 113 & 9.87 & 30.2 \\
\hline 354 & 9.0 & 0.64 & 6.81 & 7.87 & 96 & 17.07 & 33.5 \\
\hline 102 & 8.6 & 0.09 & 1.51 & 1.37 & 21 & 9.81 & 28.3 \\
\hline 229 & 8.1 & 0.89 & 5.60 & 6.49 & 116 & 7.83 & 29.5 \\
\hline 385 & 7.6 & 0.64 & 7.71 & 8.31 & 112 & 17.04 & 33.3 \\
\hline
\end{tabular}

periods of 2 to 46.5 hours during the 1-month period, were grouped separately for coffee, beans until bloom stage, and beans until pod development. Tables 1, 2, and 3 show the mean values of the recorded potential $(\Delta t)$ integrated with time, as well as the corresponding main soil, plant, and atmospheric components used to evaluate $\Delta t$ by regression analysis. It may be observed from table 1 that for beans until bloom initiation there 
exists an approximate linear 1:1 correspondence between $T s p$, and $R_{n}$ $(r=0.97)$ as long as the moisture content of the soil $(\theta)$ in the pots remains above 22 percent. The same relationship apparently remains between $R_{n}$ and $E t_{p}$ for values of $\theta$ below 22 percent, but the $T s p$ lags well behind both atmospheric parameters once $\theta$ is depleted beyond the indicated value. Although expressed in different units, the actual evapotranspiration $\left(E t_{a}\right)$ also holds an apparent linear relationship with the potential evapotranspira-

TABLE 2.-Mean values of the recorded polential $(\Delta t)$ integrated with time, as well as the corresponding mean values of the main soil, plant and weather components used to evaluate $\Delta t$ on bean plants growing in pots from their bloom initiation throughout their pod development

\begin{tabular}{|c|c|c|c|c|c|c|c|}
\hline$\Delta t$ & $\theta$ & $T s p$ & $E l_{p}$ & $R_{n}$ & $E l_{a}$ & $e_{d}$ & $T_{a}$ \\
\hline$\mu \nabla h r_{0}^{-1}$ & Percent & $M m . d a y^{-1}$ & $M m \cdot d a y^{1}$ & Mm. day-1 & $C m 0^{2}$ day $^{-1}$ & $M b$. & ${ }^{\circ} \mathrm{C}$. \\
\hline 163 & 57.2 & 1.01 & 2.96 & 3.06 & 225 & 10.98 & 28.7 \\
\hline 95 & 6.5 & 0.58 & 2.96 & 3.06 & 121 & 10.98 & 28.7 \\
\hline 125 & 50.0 & 0.97 & 3.01 & 3.02 & 227 & 13.27 & 31.2 \\
\hline 53 & 38.4 & - & 3.01 & 3.02 & 306 & 13.27 & 31.2 \\
\hline 137 & 43.9 & 3.51 & 6.78 & 7.18 & 576 & 16.85 & 33.1 \\
\hline 84 & 29.9 & - & 6.78 & 7.18 & 795 & 16.85 & 33.1 \\
\hline 74 & 40.1 & 0.17 & 1.30 & 1.10 & 94 & 9.73 & 28.5 \\
\hline 69 & 18.8 & 0.33 & 1.30 & 1.10 & 94 & 9.73 & 28.5 \\
\hline 49 & 38.0 & 2.11 & 4.65 & 5.26 & 404 & 8.15 & 29.3 \\
\hline 67 & 17.0 & 2.24 & 4.65 & 5.26 & 442 & 8.15 & 29.3 \\
\hline 52 & 35.5 & 0.55 & 1.55 & 1.55 & 114 & 7.03 & 27.1 \\
\hline 55 & 14.8 & 0.44 & 1.55 & 1.55 & 101 & 7.03 & 27.1 \\
\hline 22 & 33.6 & 0.12 & 4.13 & 4.97 & 229 & 4.25 & 27.9 \\
\hline 40 & 13.3 & 1.57 & 4.13 & 4.97 & 325 & 4.25 & 27.9 \\
\hline 173 & 32.2 & 5.06 & 11.18 & 12.87 & 831 & 14.02 & 32.3 \\
\hline 220 & 11.9 & 4.58 & 11.18 & 12.87 & 891 & 14.02 & 32.3 \\
\hline 425 & 29.4 & 4.96 & 11.30 & 12.21 & 816 & 23.24 & 35.5 \\
\hline 329 & 9.8 & 3.44 & 11.30 & 12.21 & 680 & 23.24 & 35.5 \\
\hline 45 & 53.7 & 1.16 & 1.95 & 1.96 & 205 & 6.42 & 27.3 \\
\hline 40 & 46.0 & 1.27 & 2.27 & 2.18 & 238 & 11.33 & 29.0 \\
\hline 123 & 25.5 & 2.20 & 4.04 & 3.97 & 438 & 18.60 & 31.6 \\
\hline 76 & 11.0 & 0.30 & 2.68 & 2.63 & 72 & 12.25 & 28.6 \\
\hline
\end{tabular}

tion $\left(E l_{p}\right)$ and the allied terms $T s p$ and $R_{n}$ as long as the moisture content of the soil in the pots remains above 22 percent. Therefore, it may be deducted from table 1 that until the bloom stage, beans exhibit an active transpiration rate capable of making full use of the available solar energy, or meeting essentially the potential evapotranspiration. It is suggested that under greenhouse conditions $R_{n}$ accounts for nearly all the $E t_{p}$. Because of the inconvenience in estimating the total evaporating area from the plant pots the $E t_{a}$ term is not expressed in the same units as $E t_{p}$ (or $T s p$ and $R_{n}$ ), but obviously $E t_{a}>T s p$ on each time interval. 
TABLE 3.-Mean values of the recorded potential $(\Delta \mathrm{t})$ inlegraled with time, as well as the corresponding mean values of the main soil, plant and weather componenls used to evaluate $\Delta t$ on coffee plants

growing on pots

\begin{tabular}{|c|c|c|c|c|c|c|c|}
\hline$\Delta 6$ & $\theta$ & $T s p$ & $E l_{p}$ & $R_{n}$ & $E l_{a}$ & ed & $T_{a}$ \\
\hline$\mu \nabla h r^{-1}$ & Percent & $M m \cdot$ doy $^{-1}$ & $M m \cdot d a y^{-1}$ & $M m, d a y^{-1}$ & $\mathrm{Cm}^{3} \mathrm{day}^{-3}$ & $M b$. & ${ }^{\circ} \mathrm{C}$ \\
\hline 138 & 32.7 & 3.73 & 6.64 & 6.91 & 466 & 18.38 & 32.3 \\
\hline 80 & 29.9 & 0.43 & 1.06 & 0.72 & 72 & 11.47 & 28.2 \\
\hline 98 & 28.3 & 1.96 & 3.31 & 3.25 & 240 & 11.82 & 29.3 \\
\hline 56 & 27.0 & 0.18 & 0.75 & 0.50 & 34 & 7.09 & 25.3 \\
\hline 116 & 25.5 & 2.24 & 5.07 & 5.53 & 288 & 11.35 & 29.2 \\
\hline 92 & 22.3 & 0.53 & 1.87 & 1.76 & 79 & 10.06 & 27.5 \\
\hline 168 & 19.0 & 0.43 & 2.98 & 2.92 & 77 & 14.09 & 29.7 \\
\hline 200 & 17.3 & 0.79 & 6.04 & 6.28 & 136 & 17.12 & 32.1 \\
\hline 127 & 16.6 & 0.03 & 1.13 & 0.82 & 11 & 10.60 & 27.2 \\
\hline 97 & 46.4 & 0.63 & 1.70 & 1.52 & 109 & 9.80 & 27.0 \\
\hline 91 & 43.8 & 1.32 & 3.01 & 3.00 & 221 & 10.06 & 28.2 \\
\hline 44 & 42.6 & 0.06 & 0.96 & 0.72 & 26 & 8.26 & 26.2 \\
\hline 162 & 22.3 & 0.73 & 4.57 & 4.89 & 113 & 11.34 & 29.5 \\
\hline 180 & 21.9 & 0.19 & 2.80 & 2.38 & 58 & 14.60 & 31.0 \\
\hline 13 & 21.6 & 0.03 & 1.01 & 0.80 & 16 & 7.71 & 25.3 \\
\hline 106 & 20.7 & 0.16 & 2.50 & 2.38 & 42 & 11.82 & 29.3 \\
\hline 39 & 33.0 & 0.56 & 1.58 & 1.34 & 104 & 10.58 & 27.4 \\
\hline 38 & 29.5 & 3.78 & 5.63 & 6.22 & 442 & 11.11 & 30.8 \\
\hline 93 & 26.9 & 0.81 & 2.40 & 2.38 & 136 & 11.28 & 29.1 \\
\hline 86 & 40.0 & 3.05 & 6.02 & 6.83 & 266 & 9.87 & 30.2 \\
\hline 219 & 38.7 & 8.24 & 6.81 & 7.87 & 656 & 17.07 & 33.5 \\
\hline 88 & 37.7 & 0.20 & 1.51 & 1.37 & 51 & 9.81 & 28.3 \\
\hline 78 & 36.6 & 2.32 & 5.60 & 6.49 & 211 & 7.83 & 29.5 \\
\hline 208 & 35.4 & 2.24 & 7.71 & 8.31 & 296 & 17.04 & 33.3 \\
\hline 73 & 34.3 & 0.27 & 1.62 & 1.49 & 58 & 10.07 & 29.3 \\
\hline 76 & 51.6 & 0.21 & 1.62 & 1.49 & 90 & 10.07 & 29.3 \\
\hline 79 & 33.3 & 1.80 & 4.90 & 5.45 & 162 & 9.17 & 30.5 \\
\hline 104 & 49.7 & 2.22 & 4.90 & 5.45 & 360 & 9.17 & 30.5 \\
\hline 220 & 32.4 & 3.20 & 7.41 & 7.93 & 288 & 17.07 & 33.5 \\
\hline 170 & 48.0 & 2.40 & 7.41 & 7.93 & 440 & 17.07 & 33.5 \\
\hline 84 & 31.2 & 0.35 & 1.65 & 1.31 & 61 & 14.14 & 29.5 \\
\hline 70 & 46.2 & 0.31 & 1.65 & 1.31 & 97 & 14.14 & 29.5 \\
\hline 93 & 29.2 & 0.70 & 2.56 & 2.63 & 90 & 9.84 & 29.4 \\
\hline 66 & 42.6 & 0.70 & 2.56 & 2.63 & 158 & 9.84 & 29.4 \\
\hline 86 & 29.6 & 0.32 & 2.40 & 2.34 & 124 & 11.67 & 30.0 \\
\hline 98 & 38.6 & 0.66 & 2.40 & 2.34 & 85 & 11.67 & 30.0 \\
\hline 48 & 49.4 & 1.37 & 1.95 & 1.96 & 178 & 6.42 & 27.3 \\
\hline 46 & 45.7 & 0.67 & 2.27 & 2.18 & 116 & 11.33 & 29.0 \\
\hline 153 & 36.4 & 1.16 & 4.04 & 3.97 & 204 & 18.60 & 31.6 \\
\hline 80 & 28.8 & 0.53 & 2.68 & 2.63 & 110 & 12.25 & 28.6 \\
\hline
\end{tabular}


It appears from data presented in table 2 that the transpiration rate of beans from their bloom stage throughout pod development does not maintain an approximate linear 1:1 relationship with either $R_{n}$ or $E t_{p}$, irrespective of the soil moisture content $(\theta)$. Roughly, the $T s p$ approximates 40 percent of $E t_{p}$ or $R_{n}$. The same situation is true of coffee plants. In these plants transpiration rates were cut off steeply with decreasing soil moisture $(\theta)$ and decreasing evaporative demands (low $E t_{p}, R_{n}$ or $e_{d}$ ). However, the $\Delta t$ obtained with coffee plants appears to be more sensitive to the vapor pressure saturation deficit of the air $\left(e_{d}\right)$ than to any other individual parameter, including the soil and plant parameters. In general, $\Delta t$ does not appear to be particularly sensitive to any soil, plant or weather parameter on either coffee or bean plants, when any of the three are considered individually.

TABLE 4.- Linear accounl $\left(\mathrm{r}^{2}\right)$ by individual plant, soil and weather faclors to predict the recorded potential $\Delta t$ from coffee and field bean plants under greenhouse conditions

\begin{tabular}{|c|c|c|c|}
\hline \multirow{2}{*}{ Linear function } & \multirow[t]{2}{*}{ Coffee } & \multicolumn{2}{|c|}{ Field beans- } \\
\hline & & To bloom stage & To pod development \\
\hline & $r^{2}$ & $r^{2}$ & $f^{2}$ \\
\hline$\Delta t=f(T s p)$ & 0.183 & -0.040 & 0.041 \\
\hline$\Delta t=f\left(E t_{a}\right)$ & .180 & -.059 & .053 \\
\hline$\Delta t=f(\theta)$ & -.051 & -.426 & .147 \\
\hline$\Delta t=f\left(E t_{p}\right)$ & .437 & .530 & .549 \\
\hline$\Delta t=f\left(R_{n}\right)$ & .398 & .551 & .529 \\
\hline$\Delta t=f\left(e_{d}\right)$ & .615 & .237 & .500 \\
\hline$\Delta t=f\left(T_{a}\right)$ & .576 & .508 & .549 \\
\hline
\end{tabular}

\section{PREDICTION OF $\Delta t$ BY SIMPLE LINEAR REGRESSION}

Simple linear regression of $\Delta l$ on the individual soil, plant and weather factors was initially carried out for comparison with the multiple regression of $\Delta t$ on combinations of the same factors. Table 4 shows the simple linear account $\left(r^{2}\right)$ by the soil, plant and weather factors to predict $\Delta t$, when the coffee and bean plants growing in pots were kept under greenhouse conditions. It may be observed from table 4 that evaporative demands weather factors $\left(E t_{p}, R_{n}, e_{d}\right.$, and $T_{a}$ ) contributed more to predict $\Delta t$ than either soil or plant factors. In general, their contribution was similar on coffee and beans to either bloom or pod stages of development.

\section{PREDICTION OF $\Delta t$ BY MULTIPLE REGRESSION}

Table 5 summarizes some of the main multiple regression equations in which soil, plant, and weather components are combined to estimate $\Delta l$. 
The coefficients of determination $\left(R^{2}\right)$ are indicated so that this table can be evaluated in the light of table 4. Other pertinent statistical information is presented in this table, such as the " $t$ " values of the partial regression coefficients associated with the plant-soil $\left(E t_{a}, T s p\right)$ and the weather $\left(R_{n}\right.$, $e_{d}, T_{a}, E t_{p}$ ) parameters. The tabulated " $t$ " and " $F$ " values supplement to convey an statistical appraisal of the individual and overall effects of the environmental components in contributing to predict the differential psychro potential $(\Delta t)$.

TABLE 5.-Multiple regression account of soil, plant and weather indices to predict the differential psychrometric potential $(\Delta t)$

\begin{tabular}{lrrr}
\hline \multicolumn{1}{c}{ Model of functional equation } & $R^{2}$ & "p" & $\begin{array}{c}\text { "ch" values of partial regression coefficients } \\
\text { associated with the indices }\end{array}$ \\
\hline & \multicolumn{3}{c}{ Coffee } \\
\hline$\Delta t=f\left(E t_{a}, e_{d}\right)$ & 0.619 & $30.1^{* *}$ & $0.67,6.54^{* *}$ \\
$\Delta t=f\left(T s p, e_{d}\right)$ & .628 & $31.2^{* *}$ & $1.14,6.76^{* *}$ \\
$\Delta t=f\left(E t_{a}, e_{d}, R_{n}\right)$ & .713 & $29.8^{* *}$ & $-2.13^{*}, 3.41^{* *}, 6.00^{* *}$ \\
$\Delta t=f\left(T s p, T s p^{2}, R_{n}, e_{d}\right)$ & .764 & $28.4^{* *}$ & $-3.60^{* *}, 3.51^{* *}, 4.41^{* *}$, \\
& & & $4.60^{* *}$ \\
\hline
\end{tabular}

Beans until flowering

\begin{tabular}{lrll}
\hline$\Delta t=f\left(E t_{a}, R_{n}\right)$ & 0.851 & $57.3^{* *}$ & $-6.32^{* *}, 10.33^{* *}$ \\
$\Delta t=f\left(E t_{a}, E t_{p}\right)$ & .868 & $66.1^{* *}$ & $-7.18^{* *}, 11.10^{* *}$ \\
$\Delta t=f\left(T s p, E t_{p}\right)$ & .833 & $49.9^{* *}$ & $-6.03^{* *}, 9.75^{* *}$ \\
$\Delta t=f\left(E t_{a}, R_{n}, e_{d}\right)$ & .917 & $69.7^{* *}$ & $-9.04^{* *}, 9.65^{* *}, 3.86^{* *}$ \\
\hline
\end{tabular}

Beans until pod development

\begin{tabular}{|c|c|c|c|}
\hline $\begin{array}{l}t=f\left(E t_{a}, R_{n}\right) \\
t=f\left(T s p, T_{a}\right) \\
t=f\left(E t_{a}, E t_{p}\right) \\
t=f\left(E t_{a}, R_{n}, e_{d}\right)\end{array}$ & $\begin{array}{r}0.687 \\
.704 \\
.748 \\
.865\end{array}$ & $\begin{array}{l}46.2^{* *} \\
47.7^{* *} \\
62.3^{* *} \\
87.6^{* *}\end{array}$ & $\begin{array}{l}-4.91^{* *}, 9.23^{* *} \\
-3.27^{* *}, 9.45^{* *} \\
-10.80^{* *}, 6.50^{* *} \\
-8.90^{* *}, 10.68^{* *}, 7.35^{* *}\end{array}$ \\
\hline
\end{tabular}

* Significant at the 5-percent level.

** Significant at the 1-percent level.

\section{Results of Multiple Regression with Coffee Plants}

By observing the four most significant multiple regression model equations obtained with coffee plants in table 5 it appears that the saturation vapor pressure deficit $\left(e_{d}\right)$ played the main single weather contribution to predict $\Delta t$. It was found that, as compared to the net solar radiation $\left(R_{n}\right)$, the $e_{d}$ term exerted 19.4 and 21.7 percent more contribution when combined with $E t_{a}$ and $T s p$, respectively. The air temperature $\left(T_{a}\right)$ was also a more 
effective combination with either $E t_{a}$ or $T s p$, but slightly less contributive than $e_{d}$. However, $T_{a}$ is the expression of an integrating action by the solar radiation, air humidity, and wind speed, a fact that may explain why $T_{a}$ is a more effective individual weather component than $R_{n}$. For this reason $T_{a}$ is not included in table 5. However, when $R_{n}$ is combined with $e_{d}$ and $E t_{a}$, multiple regression accounts for 71.3 percent of the fluctuations in $\Delta t$. This is 11.8 percent more than what is accounted for in $\Delta t=f\left(E t_{a}, T_{a}\right)$. This model equation is not presented in table 5 but the partial regression coefficient associated with $E t_{a}$ was nonsignificant when combined with $T_{a}$. However, when $E t_{a}$ is combined with $e_{d}$ and $R_{n}$, not only the partial regression coefficient associated with $E t_{a}$ is significant at the 5-percent level, but also those associated with $e_{d}$ and $R_{n}$ are significant at the 1-percent level.

On the other hand, the equation

$$
\Delta t=19.66 R_{n}+2.90 e_{d}-46.55 T s p+4.76 T s p^{2}-16.25
$$

accounts for 76.4 percent of the fluctuations in $\Delta t$. All the equations obtained for the models given on table 5 for coffee represent highly significant equations to predict $\Delta t$. Yet, it appears that $\Delta t$ can be more fully predicted under the experimental conditions of this study when the nonlinear reduction in $T s p$ is accounted for in coffee plants, as shown on equation /1/. When substituting $E t_{a}$ for $T s p$ on this equation it was found that the quadratic term for $E t_{a}$ was less significant than the corresponding one for $T s p$. It can be observed in table 5 that all the partial regression coefficients associated with $T s p, T s p^{2}, R_{n}$, and $e_{d}$ of equation /1/ are significant at the 1-percent level. In fact, what happened was that not only the addition of $T s p^{2}$ to the equation was highly significant but also it caused the corresponding linear term ( $T s p$ ) to be highly significant, rather than non significant as it happened when included in the equation model $\Delta t=f(T s p$, $\left.R_{n}, e_{d}\right)$, not presented in table 5. However, $e_{d}$ and $R_{n}$ also need to be in the equation for the linear and quadratic $T s p$ terms to behave as indicated. It can be observed on table 5 that the " $F$ " value connected with this quadratic equation obtained with the coffee pots is nearly as high as the other " $F$ " values of the three preceding model equations, despite the fact that equation /1/ contains four terms, giving a greater chance of error than when two or three terms are present.

\section{Results of Multiple Regression with Bean Plants}

At first sight, it may be observed by looking at the $R^{2}$ values in table 5 that bean plants, especially until flower initiation, provide the best environment (plant-soil-weather) for predicting $\Delta t$. This is fortunate because beans 
are a much more irrigation-dependent crop than coffee. This becomes obvious when one removes a bean leaf and a coffee leaf at the same time from their respective parent plants. While the coffee leaf remains apparently turgid for a time, the bean leaf begins wilting shortly after removal.

In beans, the net solar radiation is apparently the main single weather parameter that contributes to predict $\Delta t$. When combined with $E t_{a}$ they account for 85.1 percent of the fluctuations in $\Delta t$. This is 34.2 percent more than $\Delta t=f\left(E t_{a}, e_{d}\right)$ gives as $R^{2}$. Moreover, $E t_{a}$ and $R_{n}$ together account for 24.1 percent more in predicting $\Delta t$ than their individual contribution add by simple regression analysis (see table 4 ). This fact is remarkable and suggests a high degree of association between the soil-plant $E t_{a}$ and the weather variable $R_{n}$. This outstanding role of $R_{n}$ can be realized not only because of the corresponding highly significant " $\ell$ " value of the partial regression coefficient associated with this parameter but also because $R_{n}$ nearly parallels the effect of the potential evapotranspiration term $\left(E t_{p}\right)$ in the model equation $\Delta t=f\left(E t_{a}, E t_{p}\right) . E t_{p}$ integrates in a semi-rational equation the $R_{n}, e_{d}, T_{a}$, and $u$ variables, as developed by Penman (5) to estimate the potential evapotranspiration needs of plants. Thus, as in coffee $e_{d}$ is apparently the most influencing weather parameter, $R_{n}$ is apparently the corresponding one for beans, mainly until flower initiation. When evaluating $\Delta t$ in beans from the beginning until pod development, then $T_{a}$ is apparently the most controlling weather factor although it combines slightly better with $T s p$ than with $E t_{a}$.

However, the equation

$$
\Delta l=28.98 R_{n}+10.00 e_{d}-0.27 E t_{a}-28.48
$$

as obtained for beans until the flowering stage, accounts for 91.7 percent of the fluctuations in $\Delta t$ that can be attributed to changes in $R_{n}, e_{d}$ and $E t_{a}$. The three partial regression coefficients associated with these three parameters are significant at the one-percent level (see " $i$ " values on table 5). This time, incorporating the quadratic effect of $E t_{a}$, makes no significant contribution to improve the prediction of $\Delta t$ beyond that for which equation $/ 2 /$ accounts.

Soil moisture content $(\theta)$ was always much less significant than the weather factors $\left(R_{n}, e_{d}, T_{a}, E t_{p}\right)$ in combining with either $T s p$ or $E t_{a}$ to predict $\Delta t$. On the other hand, $\theta$ could substitute $T s p$ or $E t_{a}$ nearly as well when combined with potential evapotranspiration $\left(E t_{p}\right)$ to predict $\Delta t$. However, $R_{n}$ and $e_{d}$ together made the best weather combination with $E t_{a}$ and, under such conditions, $E t_{a}$ (or $T s p$ ) was more useful than $\theta$ in helping to predict $\Delta t$ of either coffee or bean plants. 


\section{THE PSYCHROMETRIC POTENTIAL $(\Delta t)$ AND IRRIGATION NEEDS}

It is apparent that the plant ( $T s p)$ or the plant-soil $\left(E t_{a}\right)$ factors benefit from the weather factors to predict $\Delta t$ with a greater precision by multiple regression analysis. This fact is most evident when the plants exhibit higher values of transpiration rates as the evaporative demands increase. It was mentioned before that in the bean plants until flowering their transpiration rates (Tsp) followed a nearly linear 1:1 trend with either $E t_{p}$ or $R_{n}$ for a wide range of $\theta$. As the plants irrigated more frequently (every 1,200 langleys of accumulated solar energy), and less frequently (every 2,500 langleys) were analyzed jointly, the present results may be looked at with optimism because the data obtained was gathered from a rather wide variety of environmental conditions of weather and of soil moisture $(\theta)$ in the plant pots.

As the potential evapotranspiration parameter $\left(E t_{p}\right)$ was more useful in contributing to the prediction of $\Delta t$ in beans, generally when these plants exhibited their most intensive transpiration rates, and, as in $\Delta t=f\left(E t_{p}\right.$, $E t_{a}$ ) one of the most significant functional relationships was obtained, it is suggested that the present method lends more effectively to actively transpiring plants, just as Penman's estimate of $E t_{p}$ (5). However, under the experimental conditions of this work, Penman's requisites for equation validity were not always satisfied. It thus is likely that by multiple regression $R_{n}, e_{d}$ and $E t_{a}$ associated to produce equation $/ 2 /$ and account for nearly 92 percent of the fluctuations in $\Delta t$, which is 5 percent greater than $E t_{p}$ and $E t_{a}$ account for in the variations of $\Delta t$ (table 5). The important fact is that if in $\Delta t=f\left(E t_{p}, E t_{d}\right)$ the Penman's equation $\left(E t_{p}\right)$ and the actual evapotranspiration calculated gravimetrically $\left(E t_{a}\right)$ combined so significantly to predict $\Delta t$ by multiple regression, it then is likely that $\Delta t$ can be integrated with time to foretell irrigation needs. As with Penman's equation, an integrator needs to be adapted to the potentiometer recorder so that, at a given predetermined integrated count in the recorder, the decision to irrigate can be made.

It is true that the soil surface junction of the thermocouple is not located in the middle of the active root zone. However, the degree to which evaporative cooling at the soil surface proceeds will depend considerably on the soil moisture content in the active root zone, possibly to 1 foot. This technique should be more useful therefore in assessing water needs of most shallow rooted crops such as vegetables. They are very sensitive to the soil water status on the first half foot or so during initial development. Further studies are needed to test this technique in the field.

A differential psychrometric potential thus has been described incorporating main soil, plant and weather factors concerned with water use by crops. The results, shown in table 5, indicate that $\Delta t$ increases as evaporative demands $\left(R_{n}, e_{d}, T_{a}, E t_{p}\right)$ increase, and decreases as $E t_{a}$ and $T s p$ decrease. 
The respective positive and negative signs preceding the " $t$ " values of the partial regression coefficients associated with each variable support this indication. These opposite and expected effects that weather and plant parameters take with respect to $\Delta t$, add support to the better understanding of the results in this study. It should be noted in table 5, however, that in the statistical analysis with coffee plants neither $E t_{a}$ nor $T s p$ assumed negative effects with respect to $\Delta t$ on the first two model equations (combined with $e_{d}$ ). Individual effects of these factors were neither statistically significant in their corresponding equations (the only two instances), and the total contribution $\left(R^{2}\right)$ to $\Delta t$ were the lowest of the 12 equations presented in the table. When the quadratic effect of $T s p$ is involved in the equation, however, it not only assumes high significance but also causes the linear term of $T s p$ to be negative and highly significant. $E t_{a}$ works similarly, though less significant. The quadratic term $\left(T s p^{2}\right)$ is positive, as should be expected from a moderating term, because coffee plants are not active "water pumps" as compared to the bean plants involved in the present study. It is thus suggested that even this intrinsic plant characteristic was accounted for in the evaluation of $\Delta t$.

\section{SUMMARY}

Results from the study of a differential psychro method for evaluating irrigation needs conducted in a greenhouse support previous laboratory results that the psychrometric potential obtained $(\Delta t)$ can be related to atmospheric conditions and to the moisture characteristics of the matrix. Weather and plant, or plant-soil parameters, combined effectively to predict $\Delta t$ in these investigations.

From coffee and from bean plants growing in pots, the actual evapotranspiration rates $\left(E t_{a}\right)$, transpiration rates $(T s p)$, and soil moisture content $(\theta)$ of the plant pots were averaged for various short time intervals, simultaneously with values of $\Delta t$ by the technique described previously by Capiel. Also determined were the corresponding mean values of weather indices, including air temperature $\left(T_{a}\right)$ vapor pressure deficit $\left(e_{d}\right)$, net solar radiation $\left(R_{n}\right)$, and potential evapotranspiration $\left(E t_{p}\right)$.

It was found by simple regression analysis that, generally, the individual plant, soil, and weather parameters correlated poorly with $\Delta t$. The linear regression of $\Delta t$ on $e_{d}$ with coffee plants was found to exhibit the highest simple account $\left(r^{2}=0.61\right)$ for the fluctuations in $\Delta t$. This is similar to the simple influence of $e_{d}$ in the previously reported laboratory study, by which the moisture characteristics of a gypsum block were also involved in the prediction of $\Delta t$.

A step-wise multiple regression of $\Delta t$ on several combinations of plant, soil and weather indices appeared to be profitable on improving the pre- 
diction of $\Delta t$. This was especially helpful when evaluating $\Delta t$ in the bean plants. These exhibited much more intensive transpiration rates than coffee under comparable environmental conditions. The model equation $\Delta t=$ $f\left(E t_{a}, R_{n}, e_{d}\right)$ accounted for 91.7 percent of the fluctuations in $\Delta t$, and all the three parameters were highly significant in their effects. This prediction even excelled $\Delta t=f\left(E t_{a}, E t_{p}\right)$ in which both indices portray the actual and the potential water needs of crops, respectively.

Multiple regression did not work as well in coffee as in bean plants. However, in $\Delta t=f\left(T s p, T s p^{2}, R_{n}, e_{d}\right)$, the linear and quadratic factors accounted for 76.4 percent of the fluctuations in $\Delta t$, and all the four parameters were highly significant. It was interesting to note that by incorporating the quadratic term $T s p^{2}$ beside the linear ( $\left.T s p\right)$, both became highly significant. In other words, by providing a moderating adjustment to the linear increase of transpiration as evaporative demands increased $\left(R_{n}, e_{d}\right), \Delta t$ could be more "effectively" predicted. It is thus suggested that intrinsic plant characteristics can also be related to the prediction of $\Delta t$ by multiple regression analysis as found with coffee plants.

\section{RESUMEN}

Un estudio de las relaciones hídricas que existen entre el suelo, la planta y el clima realizado bajo condiciones de invernadero mediante un método sicrométrico, corrobora los resultados ya obtenidos en el laboratorio, según los cuales el potencial eléctrico $(\Delta t)$ registrado guarda una estrecha relación con las condiciones atmosféricas y la humedad del suelo en combinación. En este estudio los factores hídricos de la planta, la atmósfera y el suelo se combinaron entre sí tan efectivamente que permitieron la predicción del $\Delta t$.

Se hizo un estimado de los valores promedio de la evapotranspiración, transpiración y por ciento de humedad en el suelo, en plantas de café y habichuela sembradas en tiestos. También se estimó el promedio de los componentes climáticos dentro del invernadero, a saber, temperatura del aire, radiación solar neta, déficit de saturación del vapor de aire y velocidad del viento.

Los valores promedio del potencial eléctrico $(\Delta t)$ se compararon con los parámetros representativos de la planta, el suelo y la atmósfera mediante un análisis de regresión simple y múltiple. La predicción del $\Delta t$ fue significativa bajo diversas combinaciones de los factores, especialmente en el caso de las plantas de habichuela, cuyos coeficientes de transpiración revelaron ser más altos que los del café bajo condiciones similares. La función $\Delta l=f\left(T s p, T s p^{2}, R_{n}, e_{d}\right)$ explica en el 91.7 por ciento de los casos las fluctuaciones de $\Delta t, y$ los tres parámetros envuel tos ejercen efectos al tamente significativos.

En las plantas de café la regresión múl tiple no es tan efectiva como en las de habichuela. Sin embargo; el 76.4 por ciento de la fluctuaciones en la función $\Delta t=f(T s p$, $\left.T s p^{2}, R_{n}, e_{d}\right)$ se explican por los factores incluidos. Es intersante notar que en este caso, la incorporación del componente cuadrático de transpiración $\left(T s p^{2}\right)$, en adición al lineal $(T s p)$, es causa de que ambos individualmente, lo mismo que $R_{n}$ y $e_{d}$, tengan efectos altamente significativos en la predicción del $\Delta t$. En otras palabras, tal parece que el efecto moderador de $T s p^{2}$ le imparte al efecto lineal de $T_{s} p$ el ajuste deseable para que la transpiración se asocie con la radiación solar neta y el déficit de humedad en el aire más efectivamente. 


\section{LITERATURE CITED}

1. Capiel, M., A psychrometric approach to schedule irrigation, J. Agr. Univ. P. R. 54 (2): 624-30, 1970.

2. Gardner, W. R., and Nieman, R. H., Lower limit of water availability to plants, Science 143: 1460-62, 1964.

3. Millar, A. A., Jensen, R. E., Bauer, A., and Norum, E. B., Influence of atmospheric and soil environmental parameters on the diurnal fluctuations of leaf water status of barley, Agr. Meteorol. 8: 93-105, 1971.

4. Namken, L. N., The influence of crop environment on the internal water balance of cotton, Soil Sci. Soc. Amer. Proc. 28: 12-15, 1964.

5. Penman, H. L., Natural evaporation from open water, bare soil, and grass, Proc. Royal Soc. Lond. 193: 120-46, 1948.

6. Werner, H. O., Influence of atmospheric and soil moisture conditions on diurnal variations in relative humidity of potato leaves, Agr. Exp. Sta., Univ. Nebr., Res. Bull. 176: 39 pp., 1954. 